\title{
The Pathways of the Inflated Beliefs of Responsibility and their Relationship to the Side- Thinking of Prisoners Practicing for Sports
}

\author{
Amer Saeed Al-Khagani ${ }^{1}$, Haider Jasim Nema ${ }^{1}$ \\ ${ }^{1}$ Assistant Professor and Researcher in Department of Physical Education, College of Physical Education \& \\ Sports Sciences, Babylon University, Babylon, Iraq
}

\begin{abstract}
The research included the introduction and the importance of research: The importance of identifying the paths of the inflated beliefs of responsibility and their relation to the side thinking of the sportspracticing prisoners in the Division of Positions and Altesfarat in Diwaniyah. The aim of the research is: The relationship between the paths of the inflated beliefs of responsibility and the side-thinking of sports-practicing prisoners in the Diwaniyah Positions and Altesfarat Division.
\end{abstract}

\section{The Imposition of The Search}

The researcher assumes that there is a real link between the paths of the inflated beliefs of responsibility and the side-thinking of the sports-practicing prisoners in the Diwaniyah Positions and Altesfarat Division.

The research methodology and procedures are also included in the field, as researchers used the descriptive approach in the survey style and comparative studies

The research sample, which is the sports-practicing prisoners, is used to discuss the tools used in research, testing used and statistical means.

The results were presented and discussed, and the results were presented in tabular form and then discussed. The research contained conclusions and recommendations, the most important conclusions being:

There are statistically significant moral differences between the paths of the inflated beliefs of responsibility and the side-thinking of prisoners practicing sports activity.

Keywords: pathways, inflated beliefs, sports, prisoners, side-thinking.

\section{Introduction}

The paths of the inflated beliefs of responsibility and side-thinking are greatly followed by the level of prisoners' thinking toward the right performance,

\section{Corresponding Author : \\ Amer Saeed Al-Khagani}

E-Mail: Alkhigani@Gmail.Com where researchers and sports psychology specialists have raised much controversy and the problem is crystallized as it is a feature of the Obsessivecompulsive disorder that affects his image in individuals, especially the prisoners' society, and even though it is responsibility must be everyone's personal and social responsibility. But when responsibility increases, it causes significant damage to the 
individual's life, and the individual is thus threatened by symptoms of compulsive obsession, with inflated liability as an important indicator of symptoms of compulsive obsessive disorder, particularly the prisoner community, as such the element that needs direction and guidance in society as there are developmental or developmental paths that can lead to the emergence of the inflated beliefs of responsibility among individuals who are predisposed to or face a high level of risk of obsessive compulsive disorder and lead to a high sense of responsibility and the continued existence of such inflated beliefs negative reinforcement of an individual that is acquired or learned over long periods of time causes problems serious for individual and others.

The study is important in identifying the paths of the inflated beliefs of responsibility and their relation to the side thinking of the sports-practicing prisoners in the Diwaniya positions and Altesfarat Division.

\section{Aim of Research:}

- The relationship between the paths of the inflated beliefs of responsibility and the sidethinking of prisoners in the Diwaniyah positions and Expositions Division.

The imposition of the search is:

- The researcher assumes that there is a real link between the paths of the inflated beliefs of responsibility and the side-thinking of the sportspracticing prisoners in the Diwaniyah Positions and Altesfarat Division.

\section{Method and procedures:}

Sample:

The research community includes the 261 prisoners in the Diwaniyah Positions and Altesfarat Division and the sample of the small random search from the research community (140) prisoners was selected. (14) prisoners were excluded because they were not literate, and (6) prisoners were excluded because they abstained from answering, and (17) prisoners were also excluded for the purpose of conducting the reconnaissance test, while the remaining (103) prisoners were excluded.

\section{Study Design:}

The researcher used the descriptive curriculum in the survey style and comparative studies the relational relationships to fit the nature of the problem.

\section{The variables studied:}

paths of the inflated beliefs of responsibility "as a significant feature of the compulsive obsession of the symptoms of compulsive obsession, this feature consists of five developmental or developmental pathways that lead to a sense of magnitude of responsibility in individuals with compulsive obsession disorder''(Salkovskis, P.M. and Harrison, J.) $)^{(1)}$.

4-3-2 Side-thinking: "It is the thinking one looks at the problem from different angles rather than a direct line of research that is directed to different views and may be driven away from what is familiar with thinking", (Saadi Jasim Attiyah Al-Gariri) ${ }^{(2)}$.

\section{Measures used in search:}

The researchers used a scale:

Scale the pathways of the inflated beliefs of responsibility

For the purpose of achieving the current research objectives, the researcher identified prisoners with the pathways of the inflated beliefs of responsibility as a representative sample of the current research, the researcher adopted the scale of the inflated beliefs of responsibility prepared by Coles and Sheffield 2008. And who was translated by the researcher (Aseel Latif Kitab) ${ }^{(3)}$. 
Description of the measure of the pathways of the inflated beliefs of responsibility and how to correct it:

The scale consists of (22) paragraphs distributed over (5) areas, which are strict rules, with

(5) Paragraphs, increased responsibility and (4) paragraphs, excessive protection and (5) paragraphs. The number of paragraphs (4) and the behavior causing problems was four (4) paragraphs, and the number of paragraphs (22) became paragraphs after the expert opinion was taken to fit the sample of the research. The alternatives to the answer on the scale are composed of five alternatives and (always applicable to, often applicable to, sometimes applied to, are rarely applied, never applied to) as the first alternative (5) degrees, the second alternative (4) degrees, and the third alternative (3) degrees. The fourth alternative (2) degrees, and the fifth alternative (1) degrees.

\section{Side-thinking scale:}

For the purpose of measuring lateral thinking and after informing the researchers about the studies that covered this subject, the researcher adopted the sidethinking measure prepared by (Khadija Haidar Nouri) (4), which is based on the local environment, and which was codifying by (Abeer Al-Qazwini) ${ }^{(5)}$.

\section{Describe the scale of side thinking}

The side thinking metric consists of (24) paragraphs, and the responder has to solve these paragraphs to measure side thinking, and the correction of this test is done (1, zero). If the prisoner answers the paragraph correctly, he gives (1) either the prisoner answers the wrong answer or the paragraph (zero) will be given in accordance with the correct answers given to each paragraph. The overall score for the test is calculated by adding the correct score of the paragraphs so that the maximum score the prisoner can receive is (24) and the lowest score is (zero).

\section{Scientific foundations of Tests exercises used:}

The tests are good if there are scientific bases for the test (honesty, stability, and objectivity) (Mohammed Jasim Al-Yasseri) $^{(6)}$, after the tests were determined by the test and after the survey experiment, the researcher found the scientific bases of the selected tests as follows:

\section{Content is validated}

The tests were presented through interviews to a group of (11) experts and specialists in mathematical psychology. Table 1 shows the Chi-square value of expert opinions for accepting and rejecting paragraphs measure beliefs Amplified pathways of responsibility in the field of test and measurement of taking scientific their observations and that after analyzing their views using statistical law $\left(\mathrm{Ca}^{2}\right)$.

Table (1): Indicates the validity of the liability amplified belief Path measure paragraphs

\begin{tabular}{|c|c|c|c|c|c|c|}
\hline \multirow{2}{*}{ No } & Paragraphs & \multicolumn{2}{|c|}{$\begin{array}{c}\text { relative } \\
\text { importance }\end{array}$} & \multirow{2}{*}{ Ca2 } & $\begin{array}{c}\text { Tabulated } \\
\text { value }\end{array}$ & $\begin{array}{c}\text { Significance } \\
\text { level }\end{array}$ \\
\cline { 3 - 6 } & valid & $\begin{array}{c}\text { Not } \\
\text { valid }\end{array}$ & & & \\
\hline 1 & $2,3,4,6,7,8,9,10,11,12,13,14,15,16,17$ & 11 & 0 & 11 & 3,84 & Sig \\
\hline 2 & $, 1819,20,21,22,23$ & 10 & 1 & 7,364 & 93,3 & \\
\hline
\end{tabular}

In terms of the lateral scale of thinking, it was presented to a group of experts and specialists 
(11) and table (2) showing the value of the Chisquare for expert opinions to accept and reject the side scale clauses, as the researchers found it appropriate to adopt the lateral scale for the following reasons:
- All its paragraphs were adopted by experts and specialists and no paragraph was dropped, all of which were accepted by very high agreement rates.

- Rely on the definition of side thinking of (Dibuno) in scale mode that the researchers adopted.

Table (2): Indicates the validity of the side-thinking scale paragraphs

\begin{tabular}{|c|c|c|c|c|c|c|}
\hline \multirow{2}{*}{ No } & \multirow{2}{*}{ Paragraphs } & \multicolumn{2}{|c|}{$\begin{array}{l}\text { relative } \\
\text { importance }\end{array}$} & \multirow{2}{*}{ Ca2 } & \multirow{2}{*}{$\begin{array}{l}\text { Tabulated } \\
\text { value }\end{array}$} & \multirow{2}{*}{$\begin{array}{c}\text { Significance } \\
\text { level }\end{array}$} \\
\hline & & valid & $\begin{array}{l}\text { Not } \\
\text { valid }\end{array}$ & & & \\
\hline 1 & $\begin{array}{c}1,2,3,4,5,6,7,8,9,10,11,12,13,15,16 \\
17,18,19,20,22\end{array}$ & 11 & 0 & 11 & 3,84 & Sig \\
\hline 2 & 14,21 & 10 & 1 & 7,364 & 93,3 & Sig \\
\hline
\end{tabular}

\section{Stability}

The aim of stability calculation is to estimate measurement errors and suggest methods for reducing errors."(Baran .A.R) ${ }^{(7)}$ to check the stability of the scale, the investigator used the method (test and retest).

\section{Test and retest method}

In order to calculate the stability factor, the researcher adopted the test method and retesting the paths of the inflated beliefs of responsibility and sidethinking. The tests were applied to the sample of the survey experiment, which numbered 17 prisoners on Sunday, 3/2020 and the tests were repeated after (5) days on the same group that first performed the test, as shown in table (3), where the results of the association law (Pearson) were proven. Tests have high stability.

Table (3): Shows the values of the test method and retest

\begin{tabular}{|c|c|c|c|c|}
\hline No & Variables & $\begin{array}{c}\text { Link } \\
\text { value }\end{array}$ & $\begin{array}{c}\text { Tabulated } \\
\text { value }\end{array}$ & Indication \\
\hline 1 & The paths of inflated beliefs of responsibility & 0,99 & \multirow{2}{*}{ Sig } \\
\cline { 1 - 2 } 2 & Side - thinking & 0.97 & \\
\hline
\end{tabular}




\section{The exploratory experience}

The researcher conducted the survey on a sample of 17 prisoners in the Diwaniyah Positions and Altesfarat Division at the end of Friday 6/3/2020 to test the paths of the inflated beliefs of responsibility and side thinking and aim at:

1- Identify the time needed to answer, with the average response of prisoners to test the pathways of inflated liability beliefs being 20 minutes.

2- Identify the time needed to answer, with the average response of prisoners to the side- thinking test being 30 minutes.

3- Identify obstacles a researcher may encounter in applying the final exam as some errors are avoided on the registration form.

\section{Main experience}

After the search tools with their instructions and reading became ready for application, the researchers started with the assistant team applying the search tools to the (103) prisoners who represent the prisoners in the Division of Positions and Altesfarat in Diwaniyah. The researcher applied the tests two days because of the researcher's commitment to the timing and system assigned by the Department of Positions and Altesfarat in Diwaniyah, and the researcher was careful not to pressure the sample members in terms of the nature of the answer on the scale as they need an accurate answer and ensure that the answer does not affect the other and not the test of the tracks of the inflated beliefs of responsibility was carried out on Tuesday, 10/3/2020 after the appropriate procedures and place were set up by the researcher in cooperation with the assistant staff and the Department of Positions and Altesfarat in Diwaniyah at 9.30 a.m. In the morning, all the conditions for the test were set up and the prisoners were seated in the testing room, where the scale was explained for the sample and how the scale was answered. The sample was directed that there was no mention of the guest name on the scale until they were assured that he had no indication of their identity because of the sensitivity of the situation by the prisoners and given them enough time to answer the scale.

On Thursday, 12/3/2020 the side-thinking test was applied to the search sample at the same time and the procedures adopted in testing the paths of the inflated beliefs of responsibility.

Presentation, analysis and discussion of the results- :

The researchers conducted tests on the sample research the data were statistically processed to reach the research goals, to verify the hypotheses in which the results and statistical tables were presented and analyzed, and then discussed and explained the reasons for them and supported by scientific sources.

View and analyze the results of tests of the pathways of the inflated beliefs of responsibility and the side-thinking of prisoners practicing sports activity.

Table(4): Shows the arithmetic circles, standard deviations, and the value of the link between The paths of the inflated beliefs of responsibility and side-thinking of practitioners.

\begin{tabular}{|c|c|c|c|c|c|}
\hline \multirow{2}{*}{ No } & Variables & $\begin{array}{c}\text { Arithmetic } \\
\text { mean }\end{array}$ & $\begin{array}{c}\text { standard } \\
\text { deviation }\end{array}$ & $\begin{array}{c}\text { Simple } \\
\text { Link value }\end{array}$ & Indication \\
\cline { 1 - 3 } 1 & $\begin{array}{c}\text { The paths of inflated beliefs of } \\
\text { responsibility }\end{array}$ & 68,75 & 10,099 & \multirow{2}{*}{0,891} & Sig \\
\cline { 1 - 3 } 2 & Side - thinking & 10,363 & 3,060 & \\
\hline
\end{tabular}


In light of the data extracted for the sample research, table (4) differences in variable values show the paths of the inflated beliefs of responsibility and side-thinking of practitioners. As shown in the table above, the nature of the sample research has shown a moral association between the two variables.

In the variable paths of the inflated beliefs of responsibility, the mean value (68.75) was shown, the standard deviation value $(10,099)$ and the simple correlation value $(0.891)$ was greater than the tabular value of 0.30 at a degree of freedom (42) indicating that the value of the link was significant.

The side-thinking variable for practitioners was the arithmetic mean value $(10,363)$, the standard deviation value $(3,060)$, the simple correlation value (0.891), which is greater than the tabular value (...). At a degree of freedom (...) This indicates that the value of the link is significant.

Discuss the results of the inflated pathways of accountability and the side-thinking of prisoners practicing sports activity

The results of the tests and according to the table (4) indicate that there is a significant statistical relationship between the paths of the inflated beliefs of responsibility and side- thinking. The interpretation of this relationship, and in light of current research literature, suggests that it is experience and early experience that leads an individual to feel overresponsible or over-blown, with most prisoners in the current sample of research assuming responsibilities at an abnormally early stage or early age. One of the inappropriate social upbringing methods practiced by parents, family, school and society surrounding the individual leads him to bear psychological consequences that lead him to an unconsidered behavior whose results are incorrect and illegal and thus to bear additional difficult consequences on him. The excessive belief that he is responsible for accidents and losses that can be inflicted on others such as the loss or failure of his football team to which he belongs, all of which place the individual with responsibilities beyond his control. How many players worldwide have been denied the match because of an illegal mistake or a fight within the field or with others, we think that they are the first to blame for any consequences that are issued if they do not act even if they act on their own account and because of this irresponsibility They are worried about the future, and the many stressful events they face in their daily lives require them to provide their necessities and the conflicts that ensue," they are all leading to increased responsibilities, resulting in acts that lead to legal violations, whether in terms of sports law or Criminal Law"(Najah Mahdi Shalash and Akram Subhi) ${ }^{(8)}$.

In terms of side thinking, the connection with the paths of inflated beliefs of responsibility can be explained and, as shown in table (4), the researcher attributes that connection to the ability of the individual to address the issues that face in his daily life or the events that he or she encounter in the athletic field, to act and find an alternative and appropriate solution to the event The result is that prisoners with sidethinking are able to find solutions as the psychologists see it, that this pattern is concerned with expectation, guesswork, thinking, imagery, love of surprise, and this is seen according to Ned Herman's plan. For the four breaths, these individuals are predominantly of this pattern and have a sound disposition and the ability to adjust the response to the surrounding exhilaration" (9:190).

The researchers believe that the more side thinking an individual has, the more he or she has a certain attitude toward the events that confront the individual in everyday life and the choice of the type of behavior toward others. This is not necessarily the right solution or the right thing the prisoner has taken depending on the type of situation he has encountered 
in everyday life. This shows that the prisoner has had side-thinking considerations in finding solutions to situations, whether positive or negative, and what leads him toward certain results.

Conclusions and recommendations Conclusions:

In light of the findings, the following conclusions were reached:

- There are statistically significant differences between the paths of inflated beliefs of responsibility and the side-thinking of prisoners practicing athletic activity.

\section{Recommendations:}

In the light of the conclusions reached, the research recommends that:

1- The need to care for prisoners, solve their problems, hear their opinions and think to develop their own side-thinking and discuss their different views and topics that lead them to the positive side.

2- Civil society organizations, extension institutions, and relevant departments of the Ministry of the Interior and the Ministry of Youth and Sports can benefit from the scale of the paths of the inflated beliefs and the scale of side-thinking in diagnosing prisoners with inflated beliefs, whose thinking is lateral in order to reduce their increased responsibility and develop side-thinking.

3- The need to work to strengthen themediaaspect of its various aspects (heard, read, visible) to confront the paths of the inflated beliefs of responsibility and to develop and strengthen side-thinking, which in turn helps individuals find appropriate and sound solutions to everyday events that lead the individual to the right action.

\section{Source of Funding: Self}

Conflicts of Interest statement/: This statement is signed by all the authors to indicate agreement that the above information is true and correct (a photocopy of this form may be used if there are more than 10 authors):

Ethical Clearance: Institutional Ethical Clearance

\section{References}

1- Abeer Al-Qazwini. Side thinking and its relationship to cognitive preference among university students, Masters' thesis, College of Education, Qadissiya University. 2013

2- Aseel Latif Kitab. The paths of the inflated beliefs of responsibility and their relationship to polar thinking in university students. Masters 'thesis. Babylon University, College of Education. 2019

3- Baran .A.R and et al. Psychology second edition. Halt senders. In tint and editions open. 1981

4 Khadija Haidar Nouri. The need for cognitive Lock and Self-Regulation and their relation to Diastolic Thinking, $\mathrm{PhD}$ thesis in Psychology Philosophy. Baghdad University, College of Arts, 2009

5- Mohammed Jasim Al-Yasseri. Theoretical foundations for the tests of sports education. AlNajaf Al-Ashraf, 2010

6- Najah Mahdi Shalash and Akram Subhi. Kinesthetic Learning. Basra, Basra University. 2000, T2.

7- Saadi Jasim Attiyah Al-Gariri. Teaching Thinking- his contemporary concept and orientation. 2007 Baghdad, Iraq, Al-Mustafa Press.

8- Salkovskis PM, Harrison J. Abnormal and normal obsessions - a replication. Behavior Research and Therapy. 1984 Jan 1; 22(5):549-52 